\title{
UM OLHAR DIFERENCIADO SOBRE CURRÍCULO EM EDUCAÇÃO PROFISSIONAL PÚBLICA A DISTÂNCIA PROGRAMA TELECURSO TEC
}

SÃO PAULO/SP ABRIL/2018

\author{
Lidia Ramos Aleixo de Souza - CPS - lidia.ramos@cps.sp.gov.br \\ Juçara Maria Montenegro Simonsem Santos - CPS - jucara.montenegro@cps.sp.gov.br \\ Cesar Bento de Freitas - CPS - cesar.freitas@cps.sp.gov.br
}

Tipo: Investigação Científica (IC)

Natureza: Descrição de Projeto em Andamento

Categoria: Conteúdos e Habilidades

Setor Educacional: EDUCAÇÃO MÉDIA E TECNOLÓGICA

\begin{abstract}
RESUMO
Este trabalho apresenta a concepção do currículo do Programa Telecurso TEC, o qual oferece cursos técnicos gratuitos a distância de Administração, Comércio e Secretariado em três modalidades: aberta, online e semipresencial. Com o avanço das novas tecnologias cada vez mais rápidas e integradas, os conceitos de presença e distância sofrem alterações profundas e as formas de ensinar e aprender adaptam-se às novas ferramentas disponíveis. Muda a relação de tempo, espaço e comunicação com os alunos, pois o processo de interação estende-se da sala de aula física para a virtual. Neste cenário o currículo do Telecurso TEC, objeto desta apresentação, visa garantir uma formação profissional de qualidade por meio de agrupamentos de competências correlatas e inerentes à formação, mostrando-se didaticamente oportuno, facilitando o planejamento integrado e valorizando os aspectos qualitativos sobre os quantitativos no processo de aprendizagem dos alunos
\end{abstract}

Palavras-chave: ambiente virtual; EaD; currículo, competências 


\section{Introdução}

$\mathrm{Na}$ educação a distância, forma de ensino conhecida como EaD, alunos interagem com professores e instituições, sem estar, necessariamente, no mesmo espaço físico. $\mathrm{Na}$ definição legal, educação a distância "é a modalidade educacional na qual a mediação didático-pedagógica nos processos de ensino e de aprendizagem ocorre com a utilização de meios e tecnologias de informação e comunicação, com pessoal qualificado, com políticas de acesso, com acompanhamento e avaliação compatíveis, entre outros, e desenvolva atividades educativas por estudantes e profissionais da educação que estejam em lugares ou tempos diversos”. (BRASIL, 2017).

Visando atender a uma demanda cada vez mais crescente e carente de profissionais do Eixo Tecnológico de Gestão e Negócios, foi criado o Programa Telecurso TEC, administrado pelo Centro Estadual de Educação Tecnológica Paula Souza (CPS - SP), o qual oferece três cursos: Administração, Comércio e Secretariado, conforme quadro 1.

Quadro 1 - Cursos e certificações oferecidas pelo Telecurso TEC, CEETEPS, 2018.

\begin{tabular}{|c|c|c|c|c|}
\hline \multirow{2}{*}{$\begin{array}{l}\text { Eixo } \\
\text { Tecnológico }\end{array}$} & \multirow[t]{2}{*}{ Curso } & Módulo 1 & Módulo 2 & \multirow{2}{*}{$\begin{array}{l}\text { Módulo } 3 \\
\text { Habilitação } \\
\text { Profissional }\end{array}$} \\
\hline & & \multicolumn{2}{|c|}{ Qualificação } & \\
\hline \multirow{3}{*}{$\begin{array}{l}\text { Gestão e } \\
\text { Negócios }\end{array}$} & Administração & $\begin{array}{l}\text { Assistente de } \\
\text { Planejamento }\end{array}$ & $\begin{array}{l}\text { Auxiliar } \\
\text { Administrativo }\end{array}$ & $\begin{array}{l}\text { Técnico em } \\
\text { Administração }\end{array}$ \\
\hline & Comércio & $\begin{array}{l}\text { Assistente de } \\
\text { Planejamento }\end{array}$ & $\begin{array}{l}\text { Gerente } \\
\text { Administrativo }\end{array}$ & $\begin{array}{l}\text { Técnico em } \\
\text { Comércio }\end{array}$ \\
\hline & Secretariado & $\begin{array}{l}\text { Assistente de } \\
\text { Planejamento }\end{array}$ & $\begin{array}{l}\text { Auxiliar de } \\
\text { Eventos }\end{array}$ & $\begin{array}{l}\text { Técnico em } \\
\text { Secretariado }\end{array}$ \\
\hline
\end{tabular}

Fonte: Site do Centro Paula Souza, link EAD - http://www.cps.sp.gov.br/ead

Destaca-se que o primeiro módulo é comum aos três cursos, e uma vez concluído, permite que o aluno seja admitido no módulo seguinte em qualquer dos três cursos, reduzindo o tempo de formação do aluno caso opte por fazer mais de um curso.

Os três cursos têm carga horária total entre 800 e 1000 horas cada, divididos em três módulos semestrais, fazendo com que a formação do aluno ocorra, inicialmente, ao longo de um ano e meio. Porém, o tempo de desenvolvimento de cada módulo pode ser adaptado às necessidades de uma demanda específica, diminuindo o tempo de formação técnica do aluno sem comprometer a carga horária.

Para cada módulo, há um correspondente perfil profissional, que caracteriza uma ou 
mais ocupações profissionais definidas e com identidades próprias no mercado de trabalho. Os módulos se articulam entre si, compondo itinerário formativo.

Definido o perfil profissional de conclusão (e os perfis profissionais intermediários correspondentes aos módulos) são selecionadas as competências, com base nos Referenciais Curriculares Nacionais da Educação Profissional Técnica de Nível Médio, em função do perfil definido para cada módulo. O perfil de conclusão do curso a distância é o mesmo que o adotado pelo CPS em seus cursos presenciais, estando, portanto, ambos, em consonância com o Catálogo Nacional dos Cursos Técnicos.

\section{Análise da experiência}

O currículo do Telecurso TEC é utilizado nas três formas de educação a distância oferecidas: semipresencial, online e aberta, sendo que os perfis de qualificação e formação são os mesmos.

Na modalidade semipresencial, são formadas turmas com um número predeterminado de alunos, com parte da carga horária desenvolvida em salas de aula nas escolas do CPS e parte da carga horária desenvolvida por meio do ambiente virtual de aprendizagem <http://telecursotec.cpscetec.com.br>. Os momentos presenciais semanais, acompanhados por um professor mediador de aprendizagem, têm como objetivos esclarecer e sistematizar pontos fundamentais dos cursos, desenvolver habilidades específicas e estabelecer vínculos afetivos. Para completar a carga horária do curso são desenvolvidas atividades a distância na plataforma de aprendizagem.

$\mathrm{Na}$ modalidade online são formadas turmas virtuais com um determinado número de alunos, que são permanentemente acompanhados por um professor mediador de aprendizagem (docente do CPS), servindo-se dos materiais disponíveis no programa.

Na modalidade aberta o candidato estuda por conta própria, utilizando-se dos materiais didáticos disponibilizados no site do CPS, e se inscreve para os exames presenciais semestrais que ocorrem sistematicamente em escolas polo.

Atendendo ao disposto na legislação, para a conclusão de cada curso, independentemente da modalidade de ensino escolhida, o aluno deve realizar o exame presencial - elaborado por uma equipe de especialistas na área - que é ofertado ao final de cada semestre. É considerado aprovado, o aluno que acertar mais da metade das trinta questões que são propostas. O exame é composto por questões de múltipla escolha, por meio do qual o aluno é avaliado por competências. Avaliar por 
competências significa que o aluno será avaliado não apenas em relação aos conhecimentos que construiu e às atividades que realizou, mas também em relação à sua capacidade de mobilizar e aplicar conhecimentos, habilidades, valores e atitudes para solucionar situações-problema que o desafiam, inerentes à sua formação técnica.

O desenvolvimento das atividades pelos alunos das modalidades semipresencial e online também são considerados em seu itinerário formativo. Ao desenvolver as atividades propostas em cada capítulo, o aluno retoma, pratica, aplica, desenvolve e registra conteúdos, deixando os rastros de seu conhecimento anotados no ambiente virtual de aprendizagem. Cabe aos professores acompanhar e colher estas informações, transformando-as em orientações, para que os pontos positivos sejam ressaltados, os pontos a melhorar anotados, tonando mais efetivo o aprendizado dos alunos.

O Telecurso TEC possui dois níveis de certificação, o que possibilita ao aluno, ao término de cada módulo, receber um certificado que já lhe propicie uma perspectiva de trabalho, antes de completar os três módulos, quando então, recebe a certificação de técnico.

Para a certificação de qualificação profissional (primeiro e segundo módulos) é exigida do aluno a conclusão do Ensino Fundamental. Já, para obter o certificado de técnico, o aluno deverá ter concluído o Ensino Médio.

Segue abaixo um quadro resumo dos certificados emitidos, de acordo com os módulos.

Quadro 2 - Número de alunos certificados pelo Centro Paula Souza no Programa Telecurso TEC, de 2010 até o final do primeiro semestre de 2017

\begin{tabular}{|c|c|c|c|c|}
\hline $\begin{array}{c}\text { Módulos/ } \\
\text { Modalidades }\end{array}$ & Aberta & Online & Semipresencial & Total \\
\hline I & 824 & 1.644 & 16.451 & 18.919 \\
\hline II & 730 & 1.157 & 13.190 & 15.077 \\
\hline III & 565 & 740 & 10.900 & 12.205 \\
\hline Total & 2.119 & 3.541 & 40.541 & 46.201 \\
\hline
\end{tabular}

Fonte: Gestão Acadêmica do Telecurso TEC, outubro de 2017.

Tendo como base as Diretrizes Curriculares Nacionais para a Educação Profissional de nível Técnico (Parecer CNE/CEB n. 16/99) a educação profissional desloca o eixo do trabalho educacional do desenvolvimento de conhecimentos para o desenvolvimento de competências, do ensinar para o aprender e daquilo que vai ser ensinado para o que é preciso aprender no mundo contemporâneo e no futuro.

Sabendo-se que competência profissional é a capacidade de articular, mobilizar e 
colocar em ação valores, conhecimentos e habilidades necessários para o desempenho eficiente e eficaz de atividades requeridas pela natureza do trabalho (Resolução CNE/CEB no 04/99), pode-se dizer, então, que alguém, tem competência profissional quando constitui, articula e mobiliza valores, conhecimentos e habilidades para a resolução de problemas não só rotineiros, mas também inusitados em seu campo de atuação profissional.

O currículo definido como um plano pedagógico e institucional que orienta a aprendizagem dos alunos de forma sistemática (DAVINI, 1994), é compreendido comumente como "grade curricular", "conteúdos de ensino" ou "conjunto de disciplinas".

De acordo com COLL (1994), o currículo deve proporcionar informações sobre o que ensinar (conteúdos/bases tecnológicas e objetivos), sobre quando ensinar (ordenação e sequência dos conteúdos/bases tecnológicas e objetivos), e sobre como ensinar (modo de estruturar atividades, a fim de alcançar os objetivos estabelecidos em relação a conteúdos selecionados). Desta forma, os currículos são entendidos como conjuntos integrados e articulados de situações-meio, pedagogicamente concebidos e organizados para promover aprendizagens significativas. TOSCHI (2005) cita que "um currículo base de um curso EaD deve ser mais enxuto, menos extenso que as propostas de cursos presenciais, uma vez que será complementado com as contribuições (descobertas e produções) dos diversos alunos", valorizando a interação entre todos os agentes.

Os currículos dos cursos técnicos do CPS atendem às disposições legais vigentes e seguem princípios pedagógicos atuais para a educação profissional. A identidade de cada curso é definida pelo perfil profissional de conclusão (Resolução CNE/CEB n. 04/99, artigo 8, parágrafo 1).

$\mathrm{Na}$ organização curricular dos cursos presenciais do CPS são utilizados componentes curriculares, enquanto que, no Programa Telecurso TEC utilizam-se agrupamentos de competências correlatas, inerentes à certificação modular, de acordo com o Quadro 3. 
Quadro 3: Comparativo entre a matriz curricular do primeiro módulo do curso presencial e do Telecurso TEC - Curso Técnico em Administração - CPS, 2018.

\section{Modalidade presencial Telecurso TEC \\ Componentes curriculares \\ Temas trabalhados}

\begin{tabular}{|l|l|}
\hline Gestão de pessoas I & A administração contemporânea \\
\hline Cálculos financeiros & A Administração muda com o tempo \\
\hline Gestão empresarial & A importância do planejamento \\
\hline Ética e cidadania organizacional & Tipos de planejamento \\
\hline Processos operacionais contábeis & Planejamento estratégico \\
\hline Linguagem, trabalho e tecnologia & Pesquisa de mercado \\
\hline Técnicas organizacionais & Estrutura societária \\
\hline & A estrutura da organização \\
\hline & Gestão de pessoas \\
\hline & As finanças da organização \\
\hline & Orçamento financeiro I \\
\hline Certificação: & Orçamento financeiro III \\
\hline Auxiliar administrativo & Planejamento tributário \\
\hline
\end{tabular}

Fonte: site do Centro Paula Souza - www.cps.sp.gov.br - 2018.

Os currículos dos cursos na modalidade a distância, também como forma de atender às especificidades inerentes ao seu conteúdo e formato, apresentam-se de forma diferenciada. A título exemplificativo, analisamos a organização curricular do módulo I do Curso Técnico em Administração do Telecurso TEC, demonstrada no Quadro acima.

Como se pode notar, na organização curricular do curso a distância, não estão elencados os nomes das disciplinas que o aluno cursará ao longo do módulo. Ao invés disso, estão transcritos os nomes dos capítulos do livro - agrupados por tema mostrando a integração entre o currículo e o material didático que foi especialmente desenhado para o curso, de forma multi e transdisciplinar.

$\mathrm{Na}$ interdisciplinaridade, os diversos conhecimentos sobre um objeto - inter-relacionados por um eixo integrador e sob perspectivas e enfoques específicos - dialogam entre si, questionando-se, complementando-se, aprofundando-se ou esclarecendo-se uns aos outros, embora continuem a manter sua autonomia, seus objetos específicos e suas fronteiras muito bem demarcadas. 
As práticas da inter e da transdisciplinaridade desenvolvem nos educandos a capacidade de ler a realidade sob diferentes enfoques e construir conhecimentos com informações e procedimentos das diferentes ciências, propiciando, assim, a sua formação como profissionais polivalentes.

A interdisciplinaridade favorece a revisão e a atualização permanente do currículo, facilitando o planejamento integrado e valorizando os aspectos qualitativos sobre os quantitativos no processo de aprendizagem dos alunos.

Como forma de exemplificar a sistemática do currículo, pode-se citar o tema "Gestão de Pessoas", trabalhado no capítulo dez do primeiro livro do Telecurso TEC. Este tema corresponde ao componente curricular do primeiro módulo do curso presencial "Gestão de Pessoas I", e atende às atividades relacionadas também no Plano de Curso do ensino presencial que tratam de "executar rotinas de apoio na área de recursos humanos (coletar subsídios para o planejamento de Recursos Humanos, pesquisar cargos e salários, analisar exigências para ocupação de vagas, participar dos processos de recrutamento e seleção de Recursos Humanos, utilizar manual de integração para socialização de pessoal)".

Já no curso a distância, os temas "A Administração Contemporânea", "A Administração muda com o mundo", "A Importância do Planejamento", "Tipos de Planejamento", "Planejamento Estratégico", "Planejamentos tático e operacional", correspondem ao componente curricular "Gestão Empresarial" do primeiro módulo do curso presencial, atendendo às atividades relacionadas no Plano de Curso que tratam de "auxiliar na elaboração do planejamento empresarial (elaborar relatórios, informes e documentos para elaboração e alteração das diversas formas de planejamento, participar da elaboração do plano operacional, participar na elaboração do plano tático, elaborar organogramas, cronogramas e fluxogramas, agir com eficiência e eficácia, aplicar procedimentos voltados à gestão da qualidade com sustentabilidade)".

Pela breve exemplificação feita, pode-se notar que as competências, habilidades e bases tecnológicas das disciplinas do curso técnico em administração presencial são trabalhadas nos vários temas que compõem o curso a distância do Programa Telecurso TEC, evidenciando a inter e transdisciplinaridade propostas no projeto.

Esta metodologia favorece o desenvolvimento, a mobilização e o aperfeiçoamento das diversas competências inerentes à formação do aluno, conforme pode ser exemplificado no Quadro 4, onde observamos as competências, habilidades e bases tecnológicas do primeiro tema estudado no módulo 1. 
Quadro 4: Competências, Habilidades e Bases Tecnológicas do primeiro tema da Qualificação Profissional Técnica de Nível Médio de Assistente Administrativo.

\section{I.1. A ADMINISTRAÇÄO CONTEMPORÂNEA}

\begin{tabular}{|c|c|c|}
\hline COMPETÊNCIAS & HABILIDADES & BASES TECNOLÓGICAS \\
\hline $\begin{array}{l}\text { 1. Reconhecer as funções básicas } \\
\text { da administração; } \\
\text { 2. Identificar stakeholders; } \\
\text { 3. Compreender as características } \\
\text { do administrador contemporâneo; } \\
\text { 4. Reconhecer a importância social } \\
\text { das organizações. }\end{array}$ & $\begin{array}{l}\text { 1. Aplicar conceitos de } \\
\text { eficácia e eficiência; } \\
\text { 2. Aplicar os conceitos de: } \\
\text { planejar, organizar, } \\
\text { dirigir e controlar. }\end{array}$ & $\begin{array}{l}\text { 1. Conceito de } \\
\text { administração; } \\
\text { 2. Funções da } \\
\text { administração; } \\
\text { 3. O administrador } \\
\text { contemporâneo; } \\
\text { 4. As organizações e seu } \\
\text { impacto na sociedade. }\end{array}$ \\
\hline
\end{tabular}

Fonte: Plano de curso da Habilitação Profissional Técnica de Nivel Médio de Técnico em Administração do Telecurso TEC.

O material didático do curso, por sua vez, é também um item fundamental para que a interdisciplinaridade e transdisciplinaridade dos cursos ocorra e seja praticada ao longo dos três módulos de cada um dos cursos. Composto por três recursos diversificados (vídeos, ambiente virtual e livros didáticos), proporciona a informação necessária para a construção do conhecimento, bem como atividades que complementam a formação profissional no desenvolvimento de competências e habilidades necessárias à sua área de atuação, desafiando-os com problemas a serem solucionados e projetos a serem desenvolvidos.

Os vídeos visam complementar os conteúdos dos livros didáticos, abordando os principais conceitos de uma forma criativa e dinâmica, com exemplos práticos de organizações, além de depoimentos de empresários e profissionais dos diversos setores produtivos. Estes vídeos estão disponíveis no ambiente virtual e no canal do Grupo de Estudo de Educação a Distância (GEEaD) do Centro Paula Souza, no YouTube https://www.youtube.com/user/Geeadcps

O Ambiente Virtual que tem como um dos objetivos criar uma comunidade de aprendizagem cooperativa e colaborativa, foi desenvolvido especialmente para o Programa Telecurso TEC e são disponibilizadas informações, artigos, dicas para pesquisa, fóruns de discussão e orientações continuadas a estudantes e professores orientadores de aprendizagem. É o local onde todas as informações ficam centralizadas e que podem ser consultadas a qualquer momento e de qualquer lugar.

\section{Considerações finais e perspectivas}


A educação, na sua concepção nativa, deveria encantar, seduzir, conquistar os estudantes a todo instante, apontando novas possibilidades e práticas desafiadoras, instigando a curiosidade, imaginação e criatividade dos envolvidos, de forma a desenvolver, fortificar, polir todas as faculdades físicas, intelectuais, morais e religiosas, que constituem a natureza e a dignidade humana.

As possibilidades educacionais que estão se abrindo são imensas. Cabe a nós então, educadores, estarmos em constante vigilância, fazendo a integração das mudanças tecnológicas com as competências educacionais, colaborando com a aprendizagem de forma mais integral, humana, afetiva e ética, contribuindo para a real inserção do indivíduo na sociedade.

Apesar do curso presencial e do curso a distância terem itinerários formativos diferentes, os estudantes das duas modalidades chegam ao mesmo destino: a habilitação profissional de Técnico em Administração. Dadas as particularidades inerentes a cada modalidade de ensino, a organização curricular de cada qual nem poderia se apresentar de maneira idêntica.

Não basta simplesmente transferir a organização curricular do curso presencial e transportá-la para o curso na modalidade a distância; fatores diversos como os supra demonstrados, devem ser levados em consideração para que o currículo cumpra sua função e para que se possibilite ao aluno atingir os objetivos e alcançar as competências e habilidades estabelecidas para o perfil profissional pretendido.

\section{Referências}

BRASIL. Decreto № 9.057 de 25 de maio de 2017. Regulamenta o art. 80 da Lei no 9.394, de 20 de dezembro de 1996, que estabelece as diretrizes e bases da educação nacional. Diário Oficial da União. Disponível em http://www.planalto.gov.br/ccivil_03/_Ato2015-2018/2017/Decreto/D9057.htm\#art24. Acesso em 29/03/2018

BRASIL. Resolução CNE/CEB № 04/99. Institui as Diretrizes Curriculares Nacionais para a Educação Profissional de Nível Técnico. Disponível em http://portal.mec.gov.br/setec/arquivos/pdf/RCNE_CEB04_99.pdf. Acesso em 29/03/2018

COLL, C. Psicologia e currículo. Trad. Claudia Schilling. 3ª ed. São Paulo: Ática; 1998. 
DAVINI, M. C. Currículo Integrado. In: Brasil. Ministério da Saúde. Capacitação Pedagógica para Instrutor/Supervisor - Área de Saúde. Brasília; 1994. p. 39- 48.

TOSCHI, M. S. Currículo em educação a distância. In: PRETI, o. Educação a distância: ressignificando práticas. Brasília: Liber Livro Editora, 2005, p. 167-177. 